\title{
Attitudes and Self-Practices of Pregnant Women towards Malaria Prevention and Control in Nigeria
}

\author{
Maxwell Ogochukwu Adibe , Ebere Emilia Ayogu, Nneka Uchenna Igboeli, AbdulMuminu Isah \\ Clinical Pharmacy and Pharmacy Management, University of Nigeria, Nsukka, Nigeria.
}

\section{ARTICLE INFO \\ Article history: \\ Received on: 26/10/2016 \\ Accepted on: 21/02/2017 \\ Available online: 30/05/2017}

Key words:

Attitudes, Self-practices, pregnant women, Malaria.

\begin{abstract}
Background: Malaria has become a serious health problem to developing countries leading to death of pregnant women. Regular evaluation of attitudes towards malaria disease and understanding of malaria-related practices are essential for prevention and control of the disease in endemic areas such as Nigeria.

Objective: This study was aimed at investigating the attitudes and self-practices of pregnant women towards malaria prevention and control.

Methods: We conducted a cross-sectional study using 404 pregnant women receiving antenatal care from 10 hospitals in Nsukka, Nigeria. We used a 14-item scale to assess their attitude and 10 point scale for selfpractices towards malaria prevention and control.

Results: Our results showed that $81.4 \%$ of the pregnant women had either secondary or tertiary education and $97 \%$ of them were married. About $51 \%$ and $49 \%$ of pregnant women had negative and positive attitude towards malaria prevention and control respectively. Pregnant women with low self-practice account for 59\% while $41 \%$ of them had high self-practice in malaria prevention and control.

Conclusion: Pregnant women in Nsukka had negative attitude and a corresponding low self-practice towards malaria prevention and control. Training on good malaria prevention practices is necessary for the pregnant women.
\end{abstract}

\section{INTRODUCTION}

Malaria has remained the world's most wide spread parasitic infectious disease. More than $40 \%$ of the world population lives in malarious areas (WHO, 2010). During pregnancy the Malaria infection is a major health problem in tropical and subtropical regions throughout the world. Malaria accounts for $11 \%$ of maternal deaths among pregnant and nonpregnant women in Nigeria (Peter, 2013). Research has shown that non-pregnant female adults have a significant level of immunity against malaria, while during pregnancy; these women develop decreased levels of immunity to malaria (Nwonwu et al., 2009). Another study reported that the first and second

\footnotetext{
* Corresponding Author

Maxwell Ogochukwu Adibe, Clinical Pharmacy and Pharmacy

Management, University of Nigeria, Nsukka.

Email: maxwell.adibe@unn.edu.ng
}

pregnancies are associated with a higher prevalence of malaria in women living in endemic malarious areas (Okwu, 2003). The burden of malaria infection during pregnancy is caused mainly by Plasmodium falciparum, the most common malaria species in Africa. Pregnant women are particularly vulnerable to malaria, which is a major cause of prenatal mortality, low birth weight, and maternal anaemia (Greenwood et al., 2007).

The cultural practices of people not only affect their social relationships but also affect health and disease condition (Ojua et al., 2013). In Kishe settlement area, South West Ethiopia, it was observed that some cultural doctrines affect malaria beliefs and practices which can influence the effectiveness of control strategies (Adera, 2003). One of the vital strategies employed as part of community-level interventions for strengthening home management of malaria includes improvements in access to prompt treatments; which is currently being promoted in the rural areas of Nigeria. 
To this effect, mothers, being the primary caregivers at home, are key players in control malaria (Vijayakumar et al., 2009). The Previous studies have shown that mothers' understanding of malaria and related issues is a key factor in achieving effective malaria control in endemic communities ${ }^{9,10}$. Given the prime roles play by mothers, there is the need to integrate them properly into malaria control and treatment activities (Chirdan et al., 2008; Kidane and Morrow, 2000). Since malaria causes variety of adverse consequences in pregnant women due to invasion of the placenta by Plasmodium thereby increasing the risk of adverse pregnancy outcome for the mother fetus and the new-born. Considering the involvement of women in malaria home management is paramount for malaria control and prevention. Failure to consider the knowledge, attitude, and practice about malaria in this vulnerable group may contribute to the inability of a malaria prevention program to achieve its goal (Rodríguez et al., 2003). In other words, knowledge of the attitudes and self-practices of pregnant women can be an important step in developing strategies aimed at preventing and controlling malaria. Therefore, this research work was designed to investigate the attitude and self-practices of women towards prevention and control of malaria in a sub-urban part of Nigeria.

\section{MATERIALS AND METHODS}

\section{Area of study}

The study was carried out in Nsukka local government area, in Enugu state. Nsukka has a total population of about 309,649 people with temperature ranges between 22.4 and $30.8{ }^{\circ} \mathrm{C}$ and an annual rainfall of 1520-2030 $\mathrm{mm}$. The vegetation is tropical rain forest and there are two major seasons, namely dry (November-April) and wet (May-October). Malaria transmission in the area is stable and holoendemic (Oguonu et al., 2005). It is in the malaria endemic zone and can be characterized by a stable, transmission of malaria infection throughout the year (WHO, 2010). Our study covered ten health care facilities ranging from primary to secondary health centers where antenatal services are provided.

\section{Study design and data collection}

A cross-sectional study was employed using a structured questionnaire to capture the responses. The questionnaires were administered to 404 pregnant women attending antenatal care in ten hospitals from July to August 2016. Prior to this, a pilot study was carried out using 10 questionnaires, each being administered to four different hospitals. The pregnant women were allowed to fill the questionnaires by themselves and the time taken to fill each one, difficulties encountered with respect to clarity of question were all observed and documented. The questionnaires were adjusted following the observation made. The questionnaire was prepared in simple English language but interpreted and communicated in local languages when necessary. With the use of this interviewer administered pre-tested and structured questionnaire, relevant information (data) were obtained. The questionnaire comprised of 30 questions categorized into three sections: six for demographic characteristics, 14 for self-practices among pregnant mothers and 10 for their attitude towards prevention and control of malaria. The study approval was obtained from the Department of Clinical Pharmacy Review Board and also obtained permissions from the respective hospitals' administrations. A verbal consent was also obtained from the respondents before administration of the questionnaire.

\section{Data Analysis}

Simple descriptive statistics such as frequency and percentages were used to assess the levels of both attitude and different self- practices on prevention and control of malaria in pregnancy. The level of association between high or low attitude and the different self-practices was also accessed. The statistical analysis was carried out using SPSS version 14.0 software.

\section{RESULTS}

Out of 600 questionnaires administered 404 were returned with a response rate of $67.3 \%$. The demographic characteristics showed that $71 \%$ of the women were above 35 years, $95 \%$ were married and the remaining was teenage pregnancy. The number of individuals in the household also showed that $63.4 \%$ of the women had 1-4 children while about $34.6 \%$ of them had 5-9 children and the remaining above 10 . The socio-demographic characteristics of the study population are presented in Table 1

Table 1: Demographic characteristics of pregnant women in Nsukka.

\begin{tabular}{|c|c|c|}
\hline Demographic characteristics & Frequency & Percentage (\%) \\
\hline Age group & $\mathrm{N}=404$ & \\
\hline Less than 18 years & 5 & 1.2 \\
\hline $18-35$ years & 110 & 27.2 \\
\hline Above 35 & 289 & 71.5 \\
\hline \multicolumn{3}{|l|}{ Marital Status } \\
\hline Single & 12 & 3 \\
\hline Married & 384 & 95 \\
\hline Widow & 8 & 2 \\
\hline \multicolumn{3}{|l|}{ No of Persons in the Household } \\
\hline 1 to 4 & 256 & 63.4 \\
\hline 5 to 9 & 140 & 34.6 \\
\hline 10 and more & 8 & 2 \\
\hline \multicolumn{3}{|l|}{ Level of Education } \\
\hline No formal Education & 6 & 1.5 \\
\hline Primary & 69 & 17.1 \\
\hline Secondary & 250 & 61.9 \\
\hline Tertiary qualification & 79 & 19.5 \\
\hline \multicolumn{3}{|l|}{ Socio-Economic status in Naira } \\
\hline Less than 10,000 Naira & 295 & 73 \\
\hline 10,000 to 50,000 & 87 & 21.5 \\
\hline 51 to 100,000 & 9 & 2.2 \\
\hline Above 100,000 Naira & 13 & 3.2 \\
\hline \multicolumn{3}{|l|}{ Occupation } \\
\hline Pensioners & 15 & 3.7 \\
\hline Students & 10 & 2.5 \\
\hline Housewife & 186 & 46 \\
\hline Unemployed & 6 & 1.2 \\
\hline Farmer & 42 & 10.4 \\
\hline Self-Employed & 52 & 12.9 \\
\hline Civil Servant & 95 & 23.4 \\
\hline
\end{tabular}




\section{Attitude towards prevention and control}

When posed with the statement that someone who has malaria should be avoided by people, only $3.4 \%$ disagreed while $96.5 \%$ agreed with it. The entire respondents $(100 \%)$ stated that that one can recover spontaneously from malaria without treatment and that they can treat themselves of malaria disease. About 99.3 $\%$ of the respondent agreed to the fact that malaria can be transmitted from one person to another, and at the same time 100 $\%$ responded that the best way to avoid malaria is to avoid mosquito bite and also by sleeping under mosquito net. Overall attitude of the women showed $51 \%$ and $49 \%$ for negative and positive attitude respectively. The questions and their response for assessing attitude of pregnant women towards malaria prevention and control are shown in Table 2.

Table 2: Attitudes of pregnant women towards malaria prevention and control.

\begin{tabular}{lcc}
\multicolumn{1}{c}{ Questions } & $\begin{array}{c}\text { Positive } \\
\text { Frequency }(\%)\end{array}$ & $\begin{array}{c}\text { Negative } \\
\text { Frequency (\%) }\end{array}$ \\
\hline $\begin{array}{l}\text { If someone has malaria, people } \\
\text { should avoid having close contact } \\
\text { with him or her. }\end{array}$ & $200(49.5)$ & $204(50.5)$ \\
\hline $\begin{array}{l}\text { I think that one can recover } \\
\text { spontaneously from malaria } \\
\text { without any treatment }\end{array}$ & $369(91.3)$ & $35(8.7)$ \\
\hline $\begin{array}{l}\text { I am sure that I can treat myself if I } \\
\text { get malaria }\end{array}$ & $372(92.0)$ & $32(8.0)$ \\
\hline $\begin{array}{l}\text { Malaria can be transmitted from } \\
\text { one person to another like the } \\
\text { common cold }\end{array}$ & $13(3.2)$ & $391(96.8)$ \\
\hline $\begin{array}{l}\text { I can buy anti-malaria drugs from } \\
\text { the drug shop/pharmacy to treat } \\
\text { myself when I get malaria }\end{array}$ & $20(4.9)$ & $384(95.1)$ \\
\hline $\begin{array}{l}\text { I think the best way to prevent } \\
\text { myself getting malaria is to avoid } \\
\text { getting mosquito bites }\end{array}$ & $115(28.4)$ & $289(71.6)$ \\
\hline $\begin{array}{l}\text { I will seek for advice or treatment } \\
\text { when I get malaria }\end{array}$ & $145(35.8)$ & $257(64.2)$ \\
\hline $\begin{array}{l}\text { I believe sleeping under a mosquito } \\
\text { net during the night is one way to } \\
\text { prevent myself getting malaria }\end{array}$ & $177(43.8)$ & $227(56.2)$ \\
\hline $\begin{array}{l}\text { In my opinion, mostly children and } \\
\text { pregnant women are at risk of } \\
\text { malaria }\end{array}$ & $201(49.7)$ & $203(50.3)$ \\
\hline $\begin{array}{l}\text { I might be at a greater risk of } \\
\text { getting malaria if I work and sleep } \\
\text { overnight in the garden or forest }\end{array}$ & $200(49.5)$ & $204(50.5)$ \\
\hline $\begin{array}{l}\text { I am sure that anyone can get } \\
\text { malaria }\end{array}$ & $241(59.6)$ & $163(40.4)$ \\
\hline $\begin{array}{l}\text { I think that it is dangerous when } \\
\text { malaria medicine is not taken } \\
\text { completely }\end{array}$ & $241(59.6)$ & $163(40.4)$ \\
\hline $\begin{array}{l}\text { I think that I should go to the } \\
\text { health centre/clinic to have my } \\
\text { blood tested as soon as I suspect } \\
\text { that I have suffered from malaria }\end{array}$ & $241(59.6)$ \\
$\begin{array}{l}\text { In my opinion, it is very important } \\
\text { to check for an expiry date of the } \\
\text { drug }\end{array}$ & $244(60.3)$ \\
\hline \begin{tabular}{l} 
Overall (\%) \\
\hline
\end{tabular} & $49.7)$ \\
\hline
\end{tabular}

\section{Self-practices of Pregnant women towards prevention and control of malaria}

When asked "how often do you sleep under a mosquito net", $48.8 \%$ and $51.2 \%$ of the respondents showed high and low self-practice respectively. For making sure members of the family sleep under the net and also for using mosquito repellents at home, $44.0 \%$ and $41.8 \%$ showed high self-practice while 56.0 and 58.2 $\%$ showed poor self-practice respectively. About $42.3 \%$ and 57.7 $\%$ showed high and poor self-practice respectively when they were asked how often they visit the clinic when sick. Overall selfpractice showed $59 \%$ and $41 \%$ for low and high self-practice respectively. The other questions with their respective responses are shown in Table 3.

Table 3: Self Practice levels of mothers towards malaria prevention and control.

\begin{tabular}{lcc}
\hline Questions & $\begin{array}{c}\text { High } \\
\text { Freq (\%) }\end{array}$ & $\begin{array}{c}\text { Low } \\
\text { Freq (\%) }\end{array}$ \\
\hline $\begin{array}{l}\text { How often do you sleep in a mosquito } \\
\text { net? }\end{array}$ & $197(48.8)$ & $207(51.2)$ \\
\hline $\begin{array}{l}\text { How often do other members of the } \\
\text { household sleep in mosquito nets? }\end{array}$ & $178(44.0)$ & $326(56.0)$ \\
\hline $\begin{array}{l}\text { How often do you check for holes/repair } \\
\text { mosquito nets? }\end{array}$ & $248(61.3)$ & $156(39.7)$ \\
\hline $\begin{array}{l}\text { How often do you use mosquito repellent } \\
\text { coils in your house? }\end{array}$ & $169(41.8)$ & $235(58.2)$ \\
\hline $\begin{array}{l}\text { How often do you use anti-mosquito } \\
\text { spray in your house? }\end{array}$ & $166(41.0)$ & $238(59.0)$ \\
\hline $\begin{array}{l}\text { How often do you clean/cut bushes } \\
\text { around your house? }\end{array}$ & $166(41.0)$ & $238(59.0)$ \\
\hline $\begin{array}{l}\text { How often do you clear stagnant water } \\
\text { near your house }\end{array}$ & $171(42.3)$ & $233(57.7)$ \\
\hline $\begin{array}{l}\text { How often do you visit the health center } \\
\text { when you fall sick? }\end{array}$ & $171(42.3)$ & $233(57.7)$ \\
\hline $\begin{array}{l}\text { How often do you receive visits from the } \\
\text { village Health Team? }\end{array}$ & $177(43.8)$ & $227(56.2)$ \\
\hline $\begin{array}{l}\text { How often do you forget to take your } \\
\text { malaria drug? }\end{array}$ & $9(2.2)$ & $395(97.8)$ \\
\hline \begin{tabular}{l} 
Overall (\%) \\
\hline
\end{tabular} & 41 & 59 \\
\hline
\end{tabular}

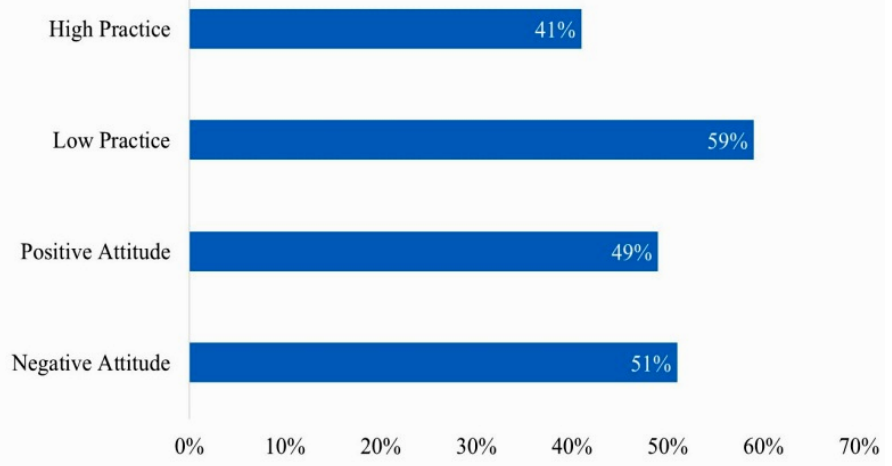

Fig. 1: Attitude and level of self-practice of the pregnant mothers.

\section{DISCUSSION}

Pregnant women in our study area showed negative attitude and a corresponding low self-practice towards malaria control and prevention. It is paramount to state that attitudinal behaviors of these pregnant women were marginal, while their self-practice was low, Fig 1. This finding might affect the utilization of anti-malarial preventive interventions and implementation of policies by pregnant women. This study is in 
total agreement with a work carried out in Anambra (Ukibe et al., 2014) and Edo (Akinleye and Ajayi, 2011), Nigeria which also recorded negative attitude and poor self-practice. The negative attitude observed differed from a study carried out in Lagos, Nigeria which recorded positive attitude towards malaria prevention and control (Iriemenam et al., 2011). The low selfpractice is in congruent with work done by Enato et al., who also recorded low self-practice among pregnant mothers.

In this era when World Health Organization, (WHO) and other Non-Governmental Organizations like Society for Family Health (SFH) Nigeria and National Malaria Control Programme (NMCP) (NMCP, 2016) and DFID Nigeria (DFID, 2012) have put in both resources and interventions to achieve drastic reduction in malaria infection, through antenatal talk show programmes, public health campaign, free distribution of long lasting insecticide treated nets and antimalarial drugs and health promotion programmes displayed over the air; it is expected that majority of pregnant women should develop positive attitude and high selfpractice towards malaria prevention and control. However, findings from this study suggest that there are other factors that could undermine the expected outcomes of these interventions. The negative attitude observed in this study may be attributed to the inadequate education seen among the respondents, as majority of them stopped at secondary education with very few having tertiary education. Another factor could be very low level of income earning, demographic data showed that a greater percentage of them earn less than 10,000 naira (about \$30) per month. This poor economic status may deny such individual of opportunity to access some of these health programmes even though they were free of charges. Some of them always shy away from most health outreach thinking they may be requested to pay for such services later. Hence, most of them may not get to receive most of the necessary health information that will help them. On the other hand, another factor that could lead to negative attitude and low self-practice could arise from lack of commitment on the side of the health care providers', especially those who come in direct contact with these pregnant women. It has been observed that malaria was inadequately addressed by medical personnel during antenatal care visit (Tobin-West and Kanu, 2016). This will have a negative impact on the pregnant women's attitude towards malaria since little attention was given to it. This suggests that improving communication about malaria prevention and control between health care workers and pregnant women is critical and could play a meaningful role in reinforcing correct attitude and self-practice

Half of the respondents stated that people should avoid close contact with a malaria patient. This implies that they see malaria disease as a contagious disease, which is a wrong notion that needs to be corrected through proper means. It is of great concern to note that almost all respondents held the view that malaria patient can recover spontaneously from malaria disease without treatment. This suggests that the respondent were not well informed on the health implications of malaria, its morbidity and mortality rate especially among children less than five years and pregnant women. This finding is in contrast with what was recorded by Enato et al., where $75 \%$ of the participants considered malaria as an important health risk. The consequence of this negative attitude is evident by the low self-practice observed among them. Almost all respondents also claimed they could treat malaria well. When asked for the best way to prevent malaria, only few respondents believes that avoiding mosquito bite and by sleeping under mosquito nets were preventive measures. This wrong notion indicates that respondents were not knowledgeable about the use of ITN for malaria prevention. This finding does not agree with the report of another study done elsewhere (Sabin et al., 2010).

More than half of the respondents showed negative attitude towards the following statements; anyone can get malaria, it is dangerous when malaria medicine is not taken completely, one should go to the health centre/clinic to have blood test as soon as he/she suspects malaria and it is important to check expiring date of a drug before taking it.

When self-practice was assessed, respondent had low self-practice towards the use of both insecticide treated net (ITN), mosquito repellent and anti-mosquito spray. This is in agreement with a study carried out in Port Harcourt (Ukibe et al., 2014; National Population Commission, 2014; Ogundana, 2013). The use of ITN among the respondents was found to be very low. This low self-practice could be attributed to either ignorance of how to use the nets, or that bed nets generate heat and disturbs sleep as was reported by previous studies (National Population Commission, 2014; Ogundana, 2013). Other factors that could lead to failure in the use of ITN as observed in another study include inadequate accommodation to hang nets, some residential house was netted, and some believe that ITNs do not work or that it causes itching, while others claim they heard ITNs killed someone or does not like ITNs (Ukibe et al., 2014). However, a greater percentage of the respondents showed high self-practice when asked how often they checked the ITN of holes and repaired them if any. Even though, some respondent agreed to the fact that avoiding mosquito bite is a major way of preventing malaria, more than half of them did not always clear stagnant water and bushes around their houses. These observations need immediate attention because by implication these women may have been taught but they are not prompted to put into practice what they have been taught.

Furthermore, more than half of the pregnant mothers did not always visit the clinic or hospital when they fall sick buttressing their negative attitude that one can recover from malaria without treatment, suggesting that they could not treat malaria. Almost all respondent showed low self-practice when asked how often they forget to take their malaria drugs, this suggests that most of them may be wrong in their claim of being able to treat malaria and above all shows that they are actually aware that it is dangerous for one not to complete his/her malaria drugs yet most of them never adhere to their drug regimen. This means that these pregnant women are not well informed concerning the consequences of not complying with drug regimen; 
such self-practices such as missing medications will lead to drug resistance which has been the major challenge in malaria disease management. There should be more vigorous awareness going on in this area so that these women will know that drug compliance and adherence is not meant for antibiotic alone but also for malarial drugs even though most malarial drug lasts for three days only.

When their socio-demographic data were matched with their responses, it was observed that women with more than four children tend to have negative attitude and a low self-practice towards malaria prevention and control than those with fewer children, while those with positive attitude and high self-practice are more of the working class (civil servants) than those who are self-employed, farmers or house wife. This negative attitude and low self-practice from these groups of respondent could be as a result of low income rate which will increase their level of poverty and decrease access to healthy living. This is supported by the fact that the socio economic statuses of the respondents contributed towards their attitude in malaria prevention and control. Women that earn between N51,000 - 100,000 (about \$150 to \$300) per month mostly had positive attitude and high self-practice toward malaria prevention and control than those earning lower. This observation is understandable because high income earner will be able to afford antenatal care in private hospitals where prompt and adequate care and attention in term of health education and treatment will be given to pregnant women.

These findings however suggest that there is some level of malaria awareness program in this area but without emphasis on actual implementation of these practices. In summary, educational campaigns informing women of reproductive age about the implications of malaria in pregnancy and children less than five years and the potential benefits of putting into practice all actions geared towards malaria control should be taken very seriously. There should be enhanced training of health personnel especially nurses and midwives to improve information on malaria disease which should go beyond conventional approaches to include activities such as communication workshops with role play during antenatal care.

Some limitations are inherent in this study. First, our respondents were recruited primarily among women attending antenatal clinics, thus our data may not have captured the opinions of pregnant women in the marginalized rural areas who cannot afford antenatal care services. Second, the respondents may have perceived that the study was aimed at assessing their knowledge or awareness on malaria; hence some respondents may have exaggerated the importance of malaria as a health issue for pregnant women or their self-practice activities

\section{CONCLUSION}

Pregnant women in Nsukka had negative attitude and a corresponding low self-practice towards malaria prevention and control. This information is of paramount importance as it gives an insight into the impact of malaria programmes done in these areas on pregnant women and quality of care given to pregnant women, especially, as relevant to control and prevention of malaria in pregnancy. There is therefore need for routine assessments of their practices to discover gaps that can be addressed through increased information during antenatal care.

\section{Financial support and sponsorship: NIL. \\ Conflict of Interests: There are no conflicts of interest.}

\section{REFERENCE}

Adera TD: Beliefs and traditional treatment of malaria in Kishe settlement area, South West Ethiopia. Ethiopia Medical Journal 2003; 41:25-34.

Ajayi IO, Falade CO, Olley BO, Yusuf B, Gbotosho S, Iyiola $\mathrm{T}$, et al: A qualitative study of the feasibility and community perception on the effectiveness of artemether-lumefantrine use in the context of home management of malaria in south-west Nigeria. BMC Health Services Research 2008; 8:119-131.

Akinleye SO, Ajayi IO: Knowledge of malaria and preventive measures among pregnant women attending antenatal clinics in a rural local government area in Southwestern Nigeria. World Health Population 2011; 12:13-22.

Chirdan OO, Zoakah AI, Ejembi CL: Impact of health education on home treatment and prevention of malaria in Jengre, North Central Nigeria. Annals of African Medicine. 2008; 7:112119.

Enato EF, Okhamafe AO, Okpere EE: A survey of knowledge, attitude and practice of malaria management among pregnant women from two health care facilities in Nigeria. Acta Obstetrica Gynecologica Scandinavica 2007; 86:33-36.

Greenwood BM, Bojang K, Whitty C, Targett G: Malaria in pregnancy. Lancet 2007 365: 1474-1480.

Iriemenam NC, Dosunmu AO, Oyibo WA, FagbenroBeyioku AF: Knowledge, attitude, perception of malaria and evaluation of malaria parasitaemia among pregnant women attending antenatal care clinic in metropolitan Lagos, Nigeria. Journal of Vector Borne Disease 2011; 48:12-17.

Kidane G, Morrow R: Teaching mothers to provide home treatment of malaria in Tigray, Ethiopia: A randomized trial. Lancet 2000; 356:550-555.

National Malaria Control Programme (NMCP) 2016. SFH and NMCP sign Global Fund Malaria Round 8, Phase 2 Grant. Available at: http://www.nmcp.gov.ng/SFH-and-NMCPsign-Global-Fund-Malaria-Round-8-Phase-2-Grant

National Population Commission. Nigeria Demographic and Health Survey 2013. Maryland, USA: IFC International/National Population Commission; 2014

Nwonwu EU, Ibekwe PC, Ugwu JI, Obarezi HC, Nwangbara OC: Prevalence of malaria parasitaemia and malaria related anaemia among pregnant women in Abakaliki, south-east Nigeria. Nigeria Journal of Clinical Practice 2009; 12:182-186

Ogundana F: Towards an effective and sustainable malaria control: Ownership and use of insecticide treated nets by pregnant women in Ekiti, Southwest Nigeria. Developing Countries Studies 2013; 3:74-183.

Oguonu T, Okafor HU, Obu HA: Care givers's knowledge, attitude and practice on childhood malaria and treatment in urban and rural comm. unities in Enugu, South-East Nigeria. Public Health 2005; 119:409-414 
Ojua T, Ishor D, Ndom P: African Cultural Practices and Health Implications for Nigeria Rural Development. International review of Mmanagement and Business Research 2013 2: 176-183

Okwu OO: The status of malaria among pregnant women: A study in Lagos, Nigeria. African Journal of Reproductive Health 2003; 7:77-83.

Peter AO: Effect of intermittent preventive treatment of malaria on the outcome of pregnancy among women attending antenatal clinic of a new Nigerian teaching hospital, Ado-Ekiti. Nigeria Medical Journal 2013; 54:170-175.

Rodríguez AD, Penilla RP, Henry-Rodríguez M, Hemingway J, Francisco Betanzos A, Hernández-Avila JE: Knowledge and beliefs about malaria transmission and practices for vector control in Southern Mexico: Salud Publication Mexico 2003; 45:110-116.

Sabin LL, Rizal A, Brooks MI, Singh MP, Tuchman J, Wylie BJ, Joyce KM, Yeboah-Antwi K, Singh N, Hamer DH: Attitudes, Knowledge, and Practices Regarding Malaria Prevention and Treatment among Pregnant Women in Eastern India. American Journal of Tropical Medicine and Hygiene 2010; 82:1010-1016.

Available

DFID Nigeria 2012. Operational Plan 2011-2015.

https:/www gov uk/government/uploads/system/uploads/attachme nt_data/file/67410/nigeria-2011.pdf
Tobin-West CI, Kanu EN. Factors influencing the use of malaria prevention methods among women of reproductive age in peri-urban communities of Port harcourt city, Nigeria. Nigerian Postgraduate Medical Journal, 2016; 23:6-11

Ukibe SN, Ikeako LC, Mbanugo JI, Obi-Okaro AC, Ukibe NR: Knowledge, Attitude and Practices of Pregnant Women concerning the use of Insecticide Treated Bed Nets (ITNs) in Anambra State, South-east Nigeria Journal of Applied Medical Sciences, 2014; 3:15-22.

Vijayakumar KN, Gunasekaran K, Sahu SS, Jambulingam P: Knowledge, attitude and practice on malaria: A study in a tribal belt of Orissa state, India with reference to use of long lasting treated mosquito nets. Acta Tropica 2009; 112:137142 .

World Health Organisation. 2010. Guidelines for the Treatment of Malaria-2nd Edition. Geneva: WHO.

\section{How to cite this article:}

Adibe MO, Ayogu EE, Igboeli NU, Isah AM. Attitudes and SelfPractices of Pregnant Women towards Malaria Prevention and Control in Nigeria. J App Pharm Sci, 2017; 7 (05): 136-141. 